\title{
Article
}

\section{Policies on bruises in premobile children: Why we need improved standards for policymaking}

\author{
Bilson, Andrew
}

Available at http://clok.uclan.ac.uk/22546/

Bilson, Andrew (2018) Policies on bruises in premobile children: Why we need improved standards for policymaking. Child \& Family Social Work, 23 (4). pp. 676-683. ISSN 1356-7500

It is advisable to refer to the publisher's version if you intend to cite from the work. http://dx.doi.org/10.1111/cfs.12463

For more information about UCLan's research in this area go to http://www.uclan.ac.uk/researchgroups/ and search for < name of research Group>.

For information about Research generally at UCLan please go to http://www.uclan.ac.uk/research/

All outputs in CLoK are protected by Intellectual Property Rights law, including Copyright law. Copyright, IPR and Moral Rights for the works on this site are retained by the individual authors and/or other copyright owners. Terms and conditions for use of this material are defined in the policies page.

\section{CLoK}

Central Lancashire online Knowledge www.clok.uclan.ac.uk

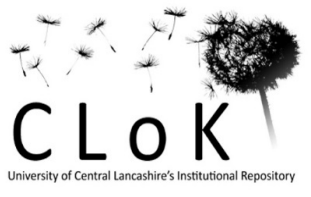




\section{Policies on Bruises in Pre-Mobile Children: Why we need improved standards for policy making.}

\section{Abstract}

This review of the 91 English children's services departments with specific policies on bruising in premobile children found a major disjuncture between research evidence and its interpretation in guidance. Many policies require all pre-mobile children found with a bruise to be seen urgently by a paediatrician and in some all bruised children are subject of a formal child protection investigation regardless of the explanations for the bruise or the views of front-line practitioners. However, the research on bruises in pre-mobile children on which these policies were based was found to be limited and contradictory and did not fully support the guidance given. National guidance given by the National Institute for Care and Health Excellence and many policies state that bruising in premobile children is suggestive of physical abuse because accidental bruising is uncommon despite the only longitudinal study of bruising showing $27 \%$ of pre-mobile children were bruised over an average of 7.6 weekly observations. The paper calls for an urgent review of these policies and guidance and improved standards for policy making.

Keywords: Child Abuse; Child Care Policy and Practice; Child Protection (Policy and Practice); Infancy; Law; Policy/Management 


\section{Introduction}

In England Local Safeguarding Children Boards (LSCB) are responsible for policy making. An increasing number of them have policies on bruising in pre-mobile children (those who cannot crawl or walk). These policies promote the view that bruises in these children are highly likely to be caused by maltreatment. Some policies require all pre-mobile children with a bruise to be subject to a formal child protection investigation under section 47 of the 1989 Children Act (s.47 enquiry) and most require a referral to a senior paediatrician. This paper provides a critical review of the research base on bruising in pre-mobile children and a survey of LSCB policies on bruising in England.

LSCBs were established in each local authority following the Children Act (2004) to coordinate local work to safeguard and promote the welfare of children. Their core function is to develop policies that specify "the action to be taken where there are concerns about a child's safety or welfare, including thresholds for intervention" (Regulation 5 of the LSCB Regulations 2006). These thresholds are intended to provide clear local criteria for actions to be taken by professionals taking account of local conditions, services and needs whilst ensuring consistency between the agencies involved. Since 2006 when LSCBs were established, the number of s.47 enquires have more than doubled (140\% increase, Department for Education, 2016) whilst the proportion that lead to a child protection plan has fallen in what has been called an investigative turn (Bilson et al, 2017).

This paper gives an overview of the legislative framework for 5.47 enquiries and the National Institute for Health and Care Excellence (NICE, 2009) guidance on when to suspect maltreatment. A review of research into the prevalence of bruising in pre-mobile children is followed by the methods used in the survey of LSCB policies. The paper then presents the results of the 91 English LSCB policies surveyed. The disjuncture between research evidence and its interpretation in guidance is 
discussed, with a focus on the implications of these policies for children and families and for good practice in safeguarding children.

\section{The legal framework}

The grounds for a s.47 enquiry is 'reasonable cause to suspect that a child ... is suffering, or is likely to suffer, significant harm' (s.47 1989 Children Act). LSCB guidance must operate within comprehensive national procedures (DfE, 2015). These require that following the acceptance of a referral by Children's Social Care (CSC) a social worker leads a multi-agency assessment and:

Where information gathered during an assessment (which may be very brief) results in the social worker suspecting that the child is suffering or likely to suffer significant harm, the local authority should hold a strategy discussion to enable it to decide, with other agencies, whether to initiate enquiries under section 47 of the Children Act 1989. (DfE 2015, p. 33)

A judicial review, $R(A B$ and $C D)$ v. The London Borough of Haringey $(2013, s .18)$, said this process of social work assessment prior to making the decision to carry out s.47 enquiries "may only be shortcircuited in exceptional circumstances". It is the role of a multi-agency strategy discussion to decide whether a s.47 enquiry is undertaken based on their assessment of the level of risk faced by the child. The judicial review stated that a s.47 enquiry is very damaging for the life, career and family relationships of parents or carers of children being investigated. Regardless of whether abuse is confirmed, a s.47 enquiry "can blight their lives irrespective of the nature and extent of the significant harm or of their involvement in it or of the reasonableness of the suspicion that generated the enquiry in the first place" (R(AB and $C D)$ v Haringey London Borough Council, 2013, section 12). Further evidence also shows unnecessary s.47 enquiries can cause parents to suffer shame and stigma (Smithson and Gibson, 2017; Gibson, 2013; Davies, 2011). 


\section{National Institute for Health and Care Excellence pathway}

The NICE pathway was published in 2009 and updated in 2014. The guidance was arrived at after "careful consideration of the evidence available" and healthcare professionals "are expected to take it fully into account when exercising their clinical judgement" (NICE, 2009 p. 2). It makes recommendations regarding a range of injuries and forms of maltreatment for children of all ages. In its overview of evidence concerning bruising the pathway cites a single systematic review carried out by Maguire, Mann, Sibert and Kemp in 2005 and funded by the NSPCC. Kemp was also the clinical advisor to the Guideline Development Group (GDG) for the NICE pathway. Despite the review not providing evidence on the epidemiology, incidence or prevalence of non-accidental bruising in premobile children the GDG agreed with Maguire et al's conclusion that in a pre-mobile child bruising is "suggestive of physical child abuse" (NICE, 2009 p. 26). In the NICE pathway to 'suspect maltreatment' is defined as having "serious concern about the possibility of child maltreatment" ( $p$. 23) and professionals who "suspect" should refer the child to CSC (NICE, 2009 p. 24). The guidance recommends in the case of a child who is not independently mobile:

Suspect child maltreatment if there is bruising or petechiae (tiny red or purple spots) that are not caused by a medical condition (for example, a causative coagulation disorder) and if the explanation for the bruising is unsuitable. (NICE, 2009 p.27).

Surprisingly, the pathway gives no definition of when a child is to be considered pre-mobile although different definitions and rates of bruising at different ages and stages of development are found in the research. The recommendation asks staff to rule out medical causes of bruising. The GDG say that before suspecting maltreatment bruises caused accidentally should be excluded although it stresses the need for stronger evidence on the nature of accidental injury in pre-mobile than more mobile children "the developmental stage of the child ... is a reasonable indicator for suspicion, in that if a child is unable to move independently, bruising is unlikely to be accidental unless there is good history of an accident" (NICE, 2009 p. 27). 


\section{Research on the rate of bruising in pre-mobile children}

The review by Maguire et al. (2005) which provided the main evidence for the NICE pathway's recommendation on bruising in pre-mobile children has now been updated and published on-line CORE info (2015). These systematic reviews of bruising are based on extensive multi-language searches - the CORE info site says that 70 multi-language search terms were used in a range of databases. These reviews were used as the starting point for the literature reviewed for this paper both because of their comprehensive nature (Sayers, 2007) and because they provide the evidence used in developing the NICE and LSCB policies. Further research on the frequency of accidental bruising in pre-mobile children was searched for by snowballing (identifying papers through accessing those referenced in these papers) and citation tracking, finding more recent papers that cite the review papers and the relevant papers on bruising using Web of Science and Google Scholar (Greenhalgh and Peacock, 2005). Papers were selected if they provided research into the incidence of accidental or non-accidental bruises in babies or pre-mobile infants and one further paper was identified (Pierce et al 2016).

The CORE Info review, like its predecessor Maguire et al (2005 p.186), concludes that bruising in a baby or in children who are not independently mobile is "suggestive of physical child abuse". The reviews rely on the statement that bruising in pre-mobile children and babies is 'very uncommon' as the basis for this claim. Neither review has a definition of the relevant age-range nor of what is meant by 'not independently mobile'. Maguire et al. (2005) cite five studies to support this statement (Carpenter, 1999; Sugar et al., 1999; Mortimer and Freemen, 1983; Labbe and Caouette, 2001; Wedgewood, 1990). The CORE Info review (2015) also cites five studies, three included in the earlier review (Carpenter, 1999; Sugar et al., 1999; Wedgewood, 1990) and two studies published since 2005 (Pierce et al, 2010; and Kemp et al, 2015a). 
Thus seven papers were identified by these reviews and an eighth paper was identified by the literature search. Four studies will not be considered in detail for the following reasons. The samples of three studies mean the research has limited value for identifying the rate of bruising in pre-mobile children. Pierce et al (2010), a study of children aged under 4 admitted to a Paediatric Intensive Care Unit, compares 42 children referred because of physical abuse with 53 children admitted because of accidental trauma. Both groups are not typical of the general population of children at this age, not least because they have high rates of bruising ( $79 \%$ and $73 \%$ respectively). The second paper by Wedgwood looked at only 11 children who were pre-mobile on a single observation and this small sample also means it cannot contribute significant evidence to the claim that bruising is very uncommon. In the third paper Carpenter (1999) studied 177 children aged 6 to 11 months at health visitor hearing test \& child health surveillance clinics finding $12.4 \%$ to be bruised. This finding is similar to the $12.8 \%$ found in this age group by Sugar et al (1999) but almost twice the $6.4 \%$ found by Pierce at al (2016). Carpenter gives information on the mobility of children finding $4.0 \%$ of the 101 children she classified as 'sits' had an accidentally caused bruise. This is lower than Sugar's finding that $5.8 \%$ of 'precruisers' aged 6 to 11 months had a bruise. However, because there were no children aged under 6 months this study- provides little information on overall rates of bruising in the main group of pre-mobile children covered by LCSB policies. The fourth citation (Mortimer and Freeman, 1983), a 34-year-old letter to a journal, reported that $1.0 \%$ of 620 0-11 month-olds had a bruise, a result significantly lower (no overlap at a 95\% confidence interval) than that found for this age group by either Pierce et al (3.5\%) or Sugar et al (5.2\%). It is not peer reviewed research with sparse details of the method or sample and was not included in the Core Info review.

The four remaining papers, one Canadian, two from the US and one from Wales varied in the categorisation of children. Two provide information by age group only (Labbe and Caouette, 2001; and Pierce et al, 2016). The third provides analysis by both the child's developmental stage and by 
age group (Sugar et al, 1999) and the final paper provides analysis by developmental stage only (Kemp at al, 2015a).

Labbe and Caouette (2001) found that 1.2\% of 246 children aged under 9 months seen at a university medical centre had a bruise (this is lower than the findings of Pierce et al, $2.0 \%$ and Sugar et al, $1.7 \%$ for this age group). However, this study excluded children seen because of accidental trauma, the group one would expect to have bruises. It also excluded children where there was suspicion of physical abuse including children with "lesions incompatible with child's development". It is not stated how many children were excluded for these reasons nor how many of the 'suspicion' cases were found to have been accidentally bruised. The sample size means that even a difference of two or three extra accidental bruises from within the excluded groups would significantly affect the findings.

Pierce et al (2016, p. 4), included 2,488 children aged under one-year-old in three paediatric emergency departments. Overall $3.5 \%$ of these children had bruises this is a lower rate than that found by Sugar et al (5.2\%) for children under one but they found a higher rate for children aged 0 to 5 months (1.3\% versus $0.6 \%$ ). However the levels of "bruising varied significantly among the 3 study sites" (2016, p. 4) with values of $6.2 \%, 4.4 \%$ and $2.6 \%$. The reason suggested for this statistically significant difference in findings was that it "may be attributable to the percentage of black patients" (p.7). However, the ethnicity of the children in the study was not recorded and this raises issues about the reliability of the study as well as its applicability in a UK setting.

Sugar et al (1999) studied 973 children under 36 months of whom 592 children were aged under one year. Given the prominence of references to this study in the LSCB procedures it is discussed in more detail. They found that $0.6 \%$ of children aged under six-months were bruised and $12.8 \%$ aged 6 to 11 months. Sugar et al defined: precruisers if they had no upright ambulation; cruisers if they walked holding on to furniture or someone's hand; and walkers if they could take two or more steps. Only $2.2 \%$ of the 0 to 14 -month-old precruisers had a bruise a finding substantially lower than the $5.4 \%$ found by Kemp at al discussed below. The authors state that: "Bruises were noted significantly more often in white than in African American children" and the editor of the journal added a note to the paper saying that she could not understand this saying: "[s]urely it can't be simply because the high melanin concentration makes [the bruises] less obvious" (DeAngelis, 1999 p. 399). Only 8\% of the 100 African American children were bruised compared to $22.7 \%$ of the white children in their study, 
a statistically significant difference. Another 160 children from other ethnic groups also had a lower rate of bruising than white children. Over a quarter of the sample were children of colour and either they were less likely to be bruised; bruises were missed or not recorded; or some other factor led to a skewed sample with less children of colour with bruises being examined. There is no analysis of bruising by a combination of ethnicity and age or stage and this limits the transferability of these findings to other populations. There are other issues about the study sample. Six children were excluded because their age fell below the age range set for their developmental stage. These children would be either aged under six months and classified as precruisers or aged under seven months and classified as walkers. It is not reported how many of them were bruised although if they were early walkers or cruisers the likelihood of bruising is very high and even one or two more bruised children would affect the findings relating to children under 6 months old. Another 5 infants who had bruises related to a medical condition were excluded and at least 2 of these were aged under 6 months-old. Finally, there were a number of exclusions because of missing or incorrect data including on sex (31), race/ethnicity (53), age (29), developmental stage (43) and 14 were excluded because there was no data on bruises at all. It is not known how many of these children were bruised and how their exclusion from elements of the study affected the findings though it raises issues about data quality in a study where the findings hinge on identifying small numbers of bruised children.

The Kemp et al (2015a) study is unlike the other studies as it involved weekly recordings by parents of whether their child had a bruise and the developmental stage reached at each collection. The sample consisted of 328 children and the data was collected 2570 times at weekly intervals with an average of 8 collections per child. A random sample of collections on different children was validated by an unannounced visit from a researcher who was in complete agreement with the parents' recording of the number and site of bruises. The rate of bruising found at the first observation of the child is used as a comparator to the bruising found on a child in a single observation in the other studies.

Kemp et al classified children as pre-mobile who were not yet crawling or cruising; early mobile if crawling or cruising; and walking. Children who were early mobile were identified in the age range 
from 4 to 18 months and $55.8 \%$ had a bruise on their first observation. There were 133 children initially classified as pre-mobile and 1010 collections made during this stage. In $6.7 \%$ of these collections a pre-mobile child had a bruise and $5.3 \%$ of these 133 children had a bruise on the first collection of data. Over the average of just 7.6 weekly observations $36(27.1 \%)$ of the pre-mobile children had one or more bruises none of which were considered to be caused by maltreatment.

For pre-mobile children who couldn't roll, $2.2 \%$ of 405 collections found bruises due to (p. 428) "bumping into mother's tooth, falling asleep on a dummy, banging themselves with a fist or rattle and a toy that was dropped on one baby." Pre-mobile children able to roll had a higher rate of $9.8 \%$ of the data collections finding a bruise including (p. 428): "12 children who had fallen or toppled over, 7 rolled into something, 4 banged into an object and 6 hit themselves with an object." Any bruising that seemed unusual or concerning was "independently reviewed by a child protection team and abuse was excluded" $(2015$, p. 430$)$ and "at no time was a suspicion of abuse raised" (p.431).

\section{Limitations in the research base}

This research into bruising above is limited in quantity and quality and the findings are contradictory. Only one British study considered levels of bruising where there are multiple observations - a common situation for many of the staff to whom LSCB policies apply. Clifford (2015), a consultant paediatrician, responding to Kemp et al complained that their finding that $27.1 \%$ pre-mobile children were bruised over an average of 7.6 weekly observations was "[l]ost in the text of the results section" and was not reported in the abstract or summary of results. In response, Kemp et al (2015b) said that the likelihood of pre-mobile children having a bruise is:

... analogous to the occurrence of the common cold. At any one time during the year, the prevalence is quite low - probably below $10 \%$ - but most people have a cold at some time during a year. 
Neither the much higher point prevalence (5.3\% is 1 in 19 children) of bruising in pre-mobile children nor the longitudinal findings of over a quarter of children having an accidental bruise over 7 weeks are mentioned in the CORE Info review which cites the research to support the statement that bruising in pre-mobile children is "very uncommon". Nor did this research trigger a review of the NICE Pathway for which Kemp was the advisor.

The differences in findings of the two most robust studies Sugar et al (1999) and Kemp et al (2015a) could be due to their methodologies or differences in their samples. Kemp reported that some children aged 4-5 months were early mobile and likely had high rates of bruising ( $55 \%$ on a first observation) whilst none of Sugar et al's pre-cruisers were aged under six months. This may have been because of different definitions of mobility or because Sugar et al excluded children "whose development appeared too advanced for their ages" (1999, p. 401). Another difference is the data collection method. In Sugar et al data was collected by 25 clinicians in seven Well Child clinics and there were no independent validations to assess the accuracy of the data gathered. Perhaps busy medical practitioners were less diligent in observing and recording minor bruises than parents who had volunteered and had more intimate knowledge of their child. Finally, the high proportion of white children (96.1\% of those where ethnicity was record) in Kemp et al's study may account for some of the difference if bruising is less detectable in children of colour who were a quarter of Sugar et al's sample.

Do these studies confirm that bruising in pre-mobile children is "suggestive of physical abuse"?

Whilst the research shows that children aged 0-5 months and pre-mobile children are less likely to have bruises than older more mobile children, this in itself does not mean that bruises are suggestive of physical abuse. Accidents involving pre-mobile children are not uncommon (Warrington et al, 2001; Picket et al, 2003). They include falls whilst being carried or because the 
child wriggled or rolled from a surface as well as bruises and cuts from having objects dropped on them or because a baby can grasp an object but not control it (Child Accident Prevention Trust, 2009 p. 5-9).

Even if accidental bruising is uncommon, for bruising of pre-mobile children to be suggestive of physical abuse a significant proportion of bruises would have to be abusive. This requires comparison between the rates of accidental and non-accidental bruising in the general population of pre-mobile children (Lopez, 2014). Neither review gives information on the prevalence of nonaccidental bruising. The nearest indicator in England is the number of children physically abused. Data published by the Department for Education (2016) shows that on the 31 $1^{\text {st }}$ March, 2016 there were 530 children aged under one year who were on child protection plans (CPP) because of physical abuse and from this it is estimated that fewer than 800 investigations leading to a CPP would have started during the year, an average of less than three per day. [This estimate assumes the ratio of CPPs started during a year to those on a CPP for under ones on $31^{\text {st }}$ March is similar to that for all children where 4,200 were on a CPP on 31 $1^{\text {st }}$ March 2016 and 6,200 CPPs started during the year]. This average of less than three children per day includes children aged over 6 months and those who were independently mobile when they were maltreated and many others whose physical maltreatment did not involve bruising.

The lowest finding for children aged under six-months (Sugar et al) would, if applicable across England, mean that there would be 1,845 children with an accidental bruise on any one day $(0.55 \%$ of 335,500 children aged under 6 months, ONS 2016). Pierce et al's finding of $1.3 \%$ of children bruised would see $4,361(1.3 \%$ of 335,500$)$ on any one day. If older children are included in these estimates then Sugar et al's finding that $5.8 \%$ of bruised precruisers aged over 6 months would have to be added to the total having bruises or similarly Carpenters finding of $4.0 \%$ of those age $6-11$ 
months who sit. Finally, Kemp et al's finding of $5.4 \%$ of pre-mobile children bruised on a first observation along with a proportion of early mobile children aged under 6 months where the rate of bruising was $55.8 \%$, would mean far higher daily numbers yet. Thus, even if the number of children placed on a CPP is a substantial underestimate of physical abuse involving a bruise on a pre-mobile child, it is still many times more likely that a child's bruise is accidental rather than abusive (Lopez, 2014).

A further important issue which limits the applicability of all but Kemp et al's study is that they focus on the rate of bruising on a single observation. In circumstances where children are monitored more frequently, for example by a social worker, health visitor or in a nursery, the repeated observations mean the likelihood of seeing a bruise will be much higher as found by Kemp et al (2015a) and shown statistically by Lux (2000) in his response to Carpenter.

\section{Method}

LSCB policies, protocols or procedures (hereafter policies) on pre-mobile infants were identified for the study initially by an email request to LSCBs. For LCSBs that did not respond to the email, policies were accessed from the internet in July and August 2016 and searched to identify whether they had a section on bruising in pre-mobile infants. In this way the policies of all 152 LSCBs (some LSCBs had joint policies but each is counted individually) were examined. It was found that 91 (59.9\%) LSCBs had a specific policy relating to finding a bruise on a pre-mobile child. The other 61 LSCB policies treat bruises in pre-mobile children similarly to injuries at other stages of development where the professional observes the nature of the injury and considers the explanation before deciding whether to refer to CSC or for an assessment by a paediatrician.

Content analysis and coding (Stemler, 2001) was undertaken of the 91 policies on pre-mobile children focussing on: the definition of when a child is considered pre-mobile; the actions that the 12 
policy requires staff to take in response to finding a bruise; and the rationale presented for these. A database was created for numerical analysis using Microsoft Excel.

\section{The LSCB policy survey findings}

Whilst there were many similarities in structure and their key message, the 91 policies varied in a number of areas. These were: the definition of the area of concern covered by the policy; the rationale for the policy; the action to be taken by frontline staff becoming aware of a bruise on a pre-mobile child; and the actions to be taken once CSC became involved.

\section{Definition of the area of concern}

There were three approaches to defining when a child was to be considered pre-mobile within the 91 LSCB s policies: fifteen policies contained no definition; 62 policies used the child's age as a primary definition; and the remaining 14 defined this solely in terms of the child's physical ability (Table 1). All but one of the age based definitions said the policy applied to all children aged under 6 months plus older pre-mobile children with a typical definition being:

\section{A baby who is not yet crawling, bottom shuffling, pulling to stand, cruising or walking independently. This includes all babies under the age of six months}

Often these definitions would specifically say that babies who can roll or sit are considered premobile. Plymouth's definition was similar except that all children up to 12 months of age were included. It should be noted that some children aged over 4 months are already crawling and most children aged four months to a year will be crawling or walking, thus these children will have a high level of accidental bruising (Kemp et al, 2015a).

The 14 policies whose definition of pre-mobile did not refer to age had definitions similar to the first part of that quoted above above but differed on whether children who can roll independently were considered pre-mobile with four seeing them as mobile. 
Rationale for the policy

Within these policies a key rationale was that accidental or self-inflicted bruises on a pre-mobile infant are 'rare' (45 LSCBs), 'very rare' (1 LSCB), 'very uncommon' (5 LSCBs), 'very unusual' (4 LSCBs) or even 'extremely rare' (4 LSCBs). Some policies cited research to support this view and often this was misinterpreted or the findings over-estimated. For example, 25 policies said that bruising is found "in less than $1 \%$ of not independently mobile infants" without citing a source. This is substantially lower than the findings of any of the three studies of pre-mobile children though it may be based on Sugar et al's findings for precruisers aged 0-5 months rather than the relevant figure of $2.2 \%$ for precruisers. Other policies misquote Kemp et al (2015a) saying that $2.2 \%$ of all pre-mobile children will have bruises (Bath and North East Somerset, Suffolk, Gloucetershire, Cornwall and Isles of Scilly) rather that the $5.4 \%$ applicable to the definitions of pre-mobile children used in these policies which include children who can roll.

Many policies go further, implying that a high proportion of bruises in pre-mobile children are likely to be caused by maltreatment. Thus, fifteen policies said that any bruise, no matter how small, is "highly predictive" of child abuse. Thirty-six LSCBs said that only "a small percentage of bruising in not independently mobile children will have an innocent explanation"

\section{Action to be taken by frontline staff}

More than three-quarters of policies ( $\mathrm{n} 70,76.9 \%$ ) allowed no discretion for those observing a bruise to take account of an explanation other than a medical one and mandated a referral to a paediatrician who was usually expected to see the child within 24 hours. In all but four of these 70 LSCBs an automatic referral to CSC was also required (Table 1). 
There were also differences in the action to be taken following referral to CSC. Most policies say that, after referral, CSC with the paediatrician should decide about further action including the need for a strategy discussion. However, eight LSCBs require a strategy discussion in all cases referred. Six of these policies give no discretion about referring the case (Leicester, Leicestershire, Lincolnshire, Rutland, Surrey and West Sussex) whilst two allow discretion to make a referral but all referrals require a strategy discussion (North East Lincolnshire and North Lincolnshire). These policies thus do not follow the national procedures which require a social worker led assessment to make the decision to call a strategy discussion.

In another five LSCB policies (Bradford, Calderdale, Kirklees, Sunderland and Wakefield) all referrals under the bruising procedure must be followed by a s.47 enquiry:

Following a referral being made and subsequent Strategy Meeting/Discussion, all referrals made under this protocol will be deemed to meet the criteria for an Enquiry under S47 Children Act 1989 (Bradford, Calderdale, Kirklees, and Wakefield)

These five LSCBs thus consider any bruise in a pre-mobile child to be 'reasonable cause' to suspect a child is suffering or is likely to suffer significant harm. In these five LSCBs this decision does not stem from a social work assessment and the decision to investigate is laid out in procedure rather than taken by a strategy discussion. Four LSCBs say that referral and s.47 enquiries should happen:

... regardless of the explanation offered by parents or carers, and regardless of the professional's own opinion about how the injury may have been caused (Bradford, Kirklees, Calderdale and Wakefield LSCBs)

\section{Discussion}

Safeguarding children is a complex and emotional area of practice. The NICE pathway and LSCB policies, in specifying when health, social work and related professionals should suspect a child in 
the general population of having been maltreated, have much in common with screening tests which aim to identify serious illnesses in Public Health programmes. The standards for decisions to implement Public Health screening programmes require high quality research to show that mortality and morbidity will be reduced; all practicable, cost-effective primary prevention interventions are implemented; and the benefit gained by individual pre-mobile children would be demonstrated to outweigh harms from intervention "for example from overdiagnosis, overtreatment, false positives, false reassurance, uncertain findings and complications" (Public Health England, 2015 section 13). These standards have not been applied to these child protection policies.

The NICE pathway has shortcomings in respect of bruising in pre-mobile infants. It lacks a definition of 'not independently mobile' despite using this as a category for suspicion. It does not provide an assessment of the "epidemiology, incidence, prevalence and natural history" (Public Health England, 2015) of physical child abuse in pre-mobile children. Amongst other things this means that the evidence of the association between a bruise and the likelihood of physical abuse is not robust. The small number of research papers on bruises in pre-mobile children, their limitations and the inconsistency of their results is not sufficiently acknowledged in the guidance and it is particularly concerning that the guidance has not been updated to take account of Kemp et al.'s (2015a) research.

LSCB policies have similar shortcomings to the NICE pathway. Despite a common evidence-base there are wide differences between definitions of when a child is pre-mobile and the actions to be taken if a bruise is discovered. Many of these policies over-state the likelihood that a bruise will arise because of maltreatment and are likely to orient staff towards suspicion and unnecessary intervention. This over-estimation of risk is also used to justify removing discretion from front line staff. The 70 policies covering nearly half of the country that require all pre-mobile children with 
bruises to be referred to a paediatrician have taken a "one-size-fits-all" approach that Clifford (2015) warns will lead to many infants having unnecessary and harmful medicals and/or s.47 enquiries and parents suffering huge anxiety and intrusion.

The eight LSCB policies where every referral must be followed by a strategy meeting do not follow the national guidance about the need for this decision to be based on an individual social work assessment. The five further LSCBs that require all referrals of pre-mobile children to be followed by a s.47 enquiry, including four saying that this should take place regardless of the explanations given by parents or the opinion of professionals, are very worrying. These policies do not meet the legal safeguards which require decision-making on the basis of individual risk and thorough interdisciplinary assessment and thus short-circuit national guidelines. These policies may be unlawful and risk legal challenge ( $R(A B$ and $C D)$ versus Haringey). It is hard to understand how a common evidence base on bruising can justify such serious consequences in these five local authorities and not in the rest of the country.

It is likely that the policies which make any bruise the threshold for referral and, in some cases, treat any bruise as 'reasonable cause' to consider a child is at risk of significant harm will do a number of disservices to the safeguarding system. In promoting the view that bruises are likely to be nonaccidental they give staff a false basis for their assessments of the risks faced by children. This may lead to increased levels of unnecessary s.47 enquiries and medical assessments sometimes involving batteries of X-rays; poorer assessments of whether bruising indicates physical abuse and an over concentration on physical indicators of concern. These policies will increase referrals and pressure on already overstretched social workers and paediatricians. They remove decision-making from those closest to the child putting faith in medical judgements and second-hand knowledge of families. As more cases of false suspicion, threats of police involvement with 'uncooperative' parents 
required by some policies, and unnecessary paediatric assessment and s.47 enquiries build up, they will further undermine the public's faith in the system. Any increased levels of referral will give more families a 'history' of suspicion by CSC making the identification of families who pose a real threat even more difficult. Suspicion of abuse has been called "toxic to mental health, and greatly damaging to self-esteem" (AIMS, 2012) and will at least put added pressure on parents whose mental health and emotional resources may already be fragile, possibly increasing the risk of harm. These policies may promote parental fear of accessing medical care (AIMS, 2012) causing a risk of harm, since petechiae and bruises can be symptoms of life threatening diseases such as meningitis.

\section{Limitations}

This paper is unable to comment on how these policies operate in practice. Currently published national statistics do not report on strategy meetings or numbers placed on child protection plans disaggregated by age and type of abuse. Further research is needed to assess the impact of these policies on trends in practice. The focus of this paper is on whether pre-mobile bruising without other indicators is a strong enough basis for suspicion of maltreatment. It does not diminish the need for vigilance and professional judgement where a child has an injury. Finally, LSCB policies for child protection are constantly under review and the ones on bruising may have changed since being accessed from the internet.

\section{Conclusion}

It is important to be vigilant when a young child is injured. It is also important that social workers, paediatricians, judges and all those working with children base their decisions on a well-informed and accurate understanding of research evidence alongside a careful assessment of the evidence in the particular case. Bruises in pre-mobile children are not as common as in older children who are more mobile, but accidents do happen. The research evidence is limited and contradictory but even the lowest findings of accidental bruising suggest it is likely to happen many times more frequently 
than maltreatment and if, as Kemp et al suggest rates of bruising are analogous to having the common cold, then most pre-mobile children will have a bruise at some point during this phase of development.

LSCB guidance in this area varies. Many LSCBs expect front-line workers to exercise professional judgement about the necessity to refer a child for paediatric assessment and referral to CSC. At the other end of the scale, five LSCBs require all bruises on pre-mobile children to be subject to a s.47 enquiry. In the 91 LCSBs with specific policies on pre-mobile children, the definitions used for when a child is considered pre-mobile vary. Sixty-one LCSBs have definitions that include some children who can roll and others who can crawl - children with a higher likelihood of accidental bruising. These variations cannot be due to local conditions, services or needs. Public Health screening programmes are subject to rigorous tests of their viability, effectiveness and appropriateness (Public Health England, 2015) to ensure they are beneficial. Similar tests have not been rigorously applied to this child protection guidance. An urgent review of these LSCB policies and the NICE pathway is required and standards similar to those used in public health screening need to be applied to policy making to ensure they don't harm those they seek to protect. 


\section{References}

Association for Improvements in Maternity Services (AIMS), (2011) The Child Protection System in England: Written evidence submitted by AIMS to Select Committee accessed 9/11/16 http://www.publications.parliament.uk/pa/cm201012/cmselect/cmeduc/writev/1514/cp29.htm Bilson, A., Featherstone, B., Martin, K., (2017) How child protection's 'investigative turn' impacts on poor and deprived communities. Family Law 47: 316-319

Carpenter, R. F. (1999). The prevalence and distribution of bruising in babies. Archives of Disease in Childhood, 80(4), 363-366.

Child Accident Prevention Trust (2009) Accidents and Child Development CAYP, Canterbury. Clifford R.G. (2015) Cross-sectional presentation of longitudinal data. Archives of Disease in Childhood Accessed http://adc.bmj.com/content/100/5/426.responses\#cross-sectionalpresentation-of-longitudinal-data 30/05/2017

CORE INFO (2015) “Patterns and sites - non-abused" accessed 28/09/2016 from http://www.coreinfo.cardiff.ac.uk/reviews/bruising/patterns/patterns-and-sites-\%E2\%80\%93-non-abused

Davies, P. (2011) 'The impact of a child protection investigation: A personal reflective account', Child and Family Social Work, 16(2):201-209.

De Angelis, J.P. (1999) Editor's Note. Archives of pediatrics \& adolescent medicine, 153(4):399. Department for Education (2016) Characteristics of children in need: 2015 to 2016: SFR 52/2016 accessed 14/11/2016 from https://www.gov.uk/government/statistics/characteristics-of-children-inneed-2015-to-2016

Department for Education (2015) Working together to safeguard children: A guide to inter-agency working to safeguard and promote the welfare of children. Department for Education, London Gibson, M. (2013) 'Shame and guilt in child protection social work: new interpretations and opportunities for practice', Child and Family Social Work, 20(3):333-343 
Greenhalgh, T., \& Peacock, R. (2005). Effectiveness and efficiency of search methods in systematic reviews of complex evidence: audit of primary sources. Bmj, 331(7524), 1064-1065.

Kemp, A. M., Dunstan, F., Nuttall, D., Hamilton, M., Collins, P., \& Maguire, S. (2015a). Patterns of bruising in preschool children-a longitudinal study. Archives of disease in childhood, 100:426-431. Kemp, A. M., Dunstan, F., Nuttall, D., Hamilton, M., Collins, P., \& Maguire, S. (2015b). Re: Crosssectional presentation of longitudinal data. Archives of Disease in Childhood Accessed http://adc.bmj.com/content/100/5/426.responses\#cross-sectional-presentation-of-longitudinaldata $30 / 05 / 2017$

Labbé, J., \& Caouette, G. (2001). Recent skin injuries in normal children. Pediatrics, 108(2):271-276. Lopez, T., (2015). Why such articles are of limited value. Archives of Disease in Childhood 99(2):1 accessed http://adc.bmj.com/content/99/2/108.responses 30/05/2017

Maguire, S., Mann, M.K., Sibert, J. and Kemp, A., (2005). Are there patterns of bruising in childhood which are diagnostic or suggestive of abuse? A systematic review. Archives of Disease in Childhood, 90(2):182-186.

Mortimer, P. E., \& Freeman, M. (1983). Are facial bruises in babies ever accidental?. Archives of disease in childhood, 58(1):75-76.

NICE (2009) Child maltreatment: When to suspect maltreatment in under 18s NICE downloaded 21/09/16 from https://www.nice.org.uk/guidance/cg89/resources/child-maltreatment-when-tosuspect-maltreatment-in-under-18s-975697287109

Pierce, M.C., Kaczor, K., Aldridge, S., O'Flynn, J. and Lorenz, D.J., 2010. Bruising characteristics discriminating physical child abuse from accidental trauma. Pediatrics, 125(1):67-74.

Public Health England, (2015). Criteria for appraising the viability, effectiveness and appropriateness of a screening programme. Downloaded from https://www.gov.uk/government/publications/evidence$\underline{\text { review-criteria-national-screening-programmes/criteria-for-appraising-the-viability-effectiveness-and- }}$ appropriateness-of-a-screening-programme 26/06/2017 
Sayers, A. (2007). Tips and tricks in performing a systematic review. British Journal of General Practice, 57(542):759-759.

Smithson, R., \& Gibson, M. (2016). Less than human: A qualitative study into the experience of parents involved in the child protection system. Child \& Family Social Work, 20:333-343 Sugar, N.F., Taylor, J.A., \& Feldman, K.W. (1999). Bruises in infants and toddlers: those who don't cruise rarely bruise. Archives of pediatrics \& adolescent medicine, 153(4):399-403.

$R(A B$ and $C D)$ v Haringey London Borough Council [2013] EWHC 416 (Admin)

Stemler, S. (2001). An overview of content analysis. Practical assessment, research \& evaluation, 7(17):137-146.

Warrington, S.A., Wright, C.M., \& ALSPAC Study Team. (2001). Accidents and resulting injuries in premobile infants: data from the ALSPAC study. Archives of disease in childhood, 85(2):104-107.

Wedgwood, J. (1990). Childhood bruising. The Practitioner, 234(1490):598. 